Doi: 10.30868/ad.v4i02.903

\title{
THE EFFECT OF CUSTOMER INTIMACY, CUSTOMERS EXPERIENCE, CUSTOMER SATISFACTION AND CUSTOMER BONDING ON CUSTOMER LOYALTY AT BANK BRI SYARIAH KCP PANDA'AN PASURUAN
}

\author{
PENGARUH CUSTOMER INTIMACY, CUSTOMERS EXPERIENCE, CUSTOMER \\ SATISFACTION DAN CUSTOMER BONDING TERHADAP LOYALITAS NASABAH \\ PADA BANK BRI SYARIAH KCP PANDA'AN PASURUAN
}

\author{
Miftahul Huda \\ Universitas Yudharta Pasuruan \\ email: miftahulhuda@yudharta.ac.id
}

\begin{abstract}
Indonesia's economic development, which is increasingly advanced, especially in the field of Islamic banking. The development of Islamic banking in Indonesia gave birth to so many investors and customers with various fundraising. High public interest in Islamic banks in saving and financing makes the banking sector more prospective. In this case, making competition in Islamic banking more competitive, especially for sharia-based banks with the same target market segment, Islamic banks have increased significantly from year to year. From this opportunity, many Islamic banks in Indonesia competed in order to meet customer needs. In this case, Islamic banks have an important role, namely to always meet customers' needs, provide products or services that are ethical following sharia principles, and provide the most comfortable access through various means anytime, anywhere. This research is an explanatory research that aims to determine the effect of Customer Intimacy, Customer Experience, Customer Bonding, Customer Satisfaction on customer loyalty. In this case, researchers take samples at Bank. In Syariah KCP Pandaan. The sample used was 92 respondents, namely customers at BRI Syariah KCP Pandaan, the sampling technique used was a pursosive $r$; the sampling method. This type of purposive research with a quantitative approach. The data used are primary data. Primary data were obtained based on results' answers to questionnaires distributed to customers at BRI Syariah KCP Pandaan Bank. Analysis of the data used is multiple linear regression analysis.
\end{abstract}

Keywords: customer intimacy, customer experience, customer satisfaction, customer bonding, loyality.

\footnotetext{
ABSTRAK

Pada perkembangan perekonomian diIndonesia yang semakin maju, khususnya dibidang perbankan syariah. Dimana Perkembangan perbankan syariah diIndonesia ini yang melahirkan begitu banyak para investor dan nasabah dengan berbagai penghimpunan dana. Tingginya minat masyarakat terhadap bank syariah dalam menabung serta pembiayaan membuat sektor perbankan semakin prospektif. Dalam hal ini membuat persaingan dalam perbankan syariah semakin kompetitif, terutama bagi bank yang berbasis syariah mempunyai sasaran segmen pasarnya sama, Bank syariah mengalami peningkatan yang cukup signifikan dari tahun ketahun. Dari peluang tersebut membuat banyak bank syariah diIndonesia berlomba-lomba bersaing guna untuk memenuhi kebutuhan nasabah. Dalam hal ini Bank syariah mempunyai peran penting yaitu untuk selalu memenuhi kebutuhan nasabah juga menyediakan produk atau layanan yang beretika sesuai dengan prinsip-prinsip syariah, dan menyediakan akses ternyaman melalui berbagai sarana kapanpun dan dimanapun. Penelitian ini merupakan penelitian explanatory research yang bertujuan untuk mengetahui pengaruh
} 
Customer Intimacy, Customer experience, Customer satisfaction, Customer Bonding, terhadap loyalitas nasabah, dalam hal ini peniliti mengambil sampel di Bank BRI Syariah KCP Pandaan. Sampel yang digunakan sejumlah 92 responden yaitu nasabah di Bank BRI Syariah KCP Pandaan, teknik pengambilan sampel menggunakan metode pursosive random sampling. Jenis Penelitian ini adalah penelitian dengan pendekatan kuantitatif. Data yang digunakan adalah data primer. Data primer diperoleh berdasarkan jawaban responden terhadap angket yang di bagikan kepada nasabah di Bank BRI Syariah KCP Pandaan. Analisis data yang digunakan adalah analisis regresi linear berganda.

Kata Kunci: customer intimacy, customer experience, customer satisfaction, customer bonding, loyalitas.

\section{A. Pendahuluan}

Pada perkembangan perekonomian di Indonesia yang semakin maju, khususnya dibidang perbankan syariah. Dimana Perkembangan perbankan syariah diIndonesia ini yang melahirkan begitu banyak para investor dan nasabah dengan berbagai penghimpunan dana. Tingginya minat masyarakat terhadap bank syariah dalam menabung serta pembiayaan membuat sektor perbankan semakin prospektif. Dalam hal ini membuat persaingan dalam perbankan syariah semakin kompetitif, terutama bagi bank yang berbasis syariah mempunyai sasaran segmen pasarnya sama, Bank syariah mengalami peningkatan yang cukup signifikan dari tahun ketahun. Dengan perkembangannya mampu meningkatkan kontribusi untuk memperkuat stabilitas perekonomian nasional. Menurut sumber yang kami peroleh pada CNBC Indonesia Perkembangan syariah diIndonesia bisa dilihat dalam perkembangan jumlah nasabah pada bank umum syariah dari tahun lalu, Seperti dijelaskan diartikel
CNBC Indonesia bahwa jumlah nasabah perbankan syariah terus tumbuh hingga menembus 23,18 juta pada akhir agustus 2018. Jumlah nasabah tersebut tumbuh sebesar $13 \%$ dibandingkan dengan tahun 2017 yang tercatat 20,48 juta (https://www.cnbcindonesia.com/syariah/2 0181026075105-29-39119 /jumlahnasabah-bank-syariah-tembus-rekor-ayohijrah).

Dari pertumbuhan tersebut, membuat Bank syariah mempunyai peluang untuk mengembangkan usahanya. Dikarenakan maraknya produk yang berbasis syariah saat ini membuat masyarakat muslim lebih dominan memilih produk yang bergambarkan syariah. Dari peluang tersebut membuat banyak bank syariah diIndonesia berlomba-lomba bersaing guna untuk memenuhi kebutuhan nasabah. Dalam hal ini Bank syariah mempunyai peran penting yaitu untuk selalu memenuhi kebutuhan nasabah juga menyediakan produk atau layanan yang beretika sesuai dengan prinsip-prinsip syariah, dan 
menyediakan akses ternyaman melalui berbagai sarana kapanpun dan dimanapun.

Bank syariah saat ini banyak dijumpai diantaranya Bank BCA Syariah, Bank BNI Syariah, Bank BRI Syariah, Bank Muamalat Indonesia, Bank Bukopin Syariah, Bank Jabar banten Syariah, dll. Dari banyaknya bank tersebut yang ingin peneliti jadikan objek penelitian adalah BRI Syariah, Dimana BRI Syariah adalah lembaga perbankan syariah. Bank ini berdiri pada tahun 1969, dahulu bernama Bank Jasa Artha, lalu diambil alih Bank Rakyat Indonesia, menjadi Bank Umum Syariah pada 2008. Layanan yang dipersembahkan BRI Syariah, saat ini telah memiliki system layanan BRI Syariah Mobile atau yang biasa disebut dengan BRIS Online. Bris Online sendiri adalah layanan yang memungkinkan nasabah dari bank BRI syariah untuk memperoleh informasi perbankan serta melakukan transaksi baik finansial maupun non finansial melalui perangkat telepon seluler atau handpone, Penggunaan BRIS Online sendiri saat ini masih dikombinasikan dengan Short Message service atau SMS yang secara aman dan mudah melakukan verifikasi terkait setiap transaksi yang akan nasabah laukan (https://id.wikipedia.org/wiki/Bank_BRI_S yariah Di update pada 22 November 2016). BRI syariah membuktikan kesuksesannya dengan menerima penghargaan Best MidCap Equity Deal Award in Southeast Asia dari Majalah Alpa Southeast Asia. Penghargaan ini diserahkan langsung oleh Siddiq Bazarwala, CEO and publisher Alpa Southeast Asia kepada Direktur Utama BRI Syariah Moch. Hadi Santoso diKuala Lumpur Malaysia, Penghargaan ini merupakan pengakuan terhadap kesuksesan IPO BRI Syariah dibulan Mei 2018. Saat itu BRI Syariah melepas 27 persen sahamnya, sukses mengantarkan anak perusahaan BUMN ini menjadi bank milik BUMN pertama yang melantai dibursa. Strategi IPO BRI Syariah dinilai Alpha Southeast Asia menarik, dan menjadi contoh positif. Harga saham BRI Syariah juga terus menunjukkan pertumbuhan. Jumlah investor BRI Syaria $\mathrm{h}$ juga meningkat. Saat IPO jumlah investor sekitar 6.000. kini, sudah mencapai lebih dari 13 ribu investor (https://republika.co.id/berita/pnhae9368/b ri-syariah-terima-penghargaan-dariemalpha-southeast-asiaem di upload pada senin 25 februari 2019).

Dari berita yang dikutip Top Brand Award merupakan penghargan tertinggi di bidang merek yang hanya diberikan kepada merek-merek yang meraih posisi puncak. Hanya merek yang benar-benar kuat yang mampu meraihnya. Oleh karena itu penghargaan ini valid dan reliable karena 
berdasarkan pilihan konsumen." jelas Indri. Ia mengungkapkan, hal ini merupakan berita gembira bagi BRI Syariah, dengan terpilihnya BRI Syariah sebagai peraih Top Brand Award 2019 pada kategori Tabungan Syariah. Karena saat ini BRI Syariah ditantang untuk promosi tanpa biaya yang efektif di era digital marketing dan terus digaungkan melalui media sosial BRI Syariah (https://republika.co.id/berita/pna1lf384/ek onomi/syariahekonomi/19/02/16/pn0mgw453-tabunganfaedah-brisyariah-jadi-favorit-milenial di publis pada tanggal 16 februari 2019).

\section{TABUNGAN SYARIAH}

\section{BRAND}

\section{BRI Syariah}

Mandiri Syariah (BSM)

BNI Syariah

BCA Syariah

Bank Muamalat

\section{TBI 2019}

\section{$29.1 \% \quad$ TOP}

$21.2 \%$

TOP

$20.0 \%$

TOP

\section{Sumber : Top Brand Kategori Tabungan Syari'ah tahun 2019}

Namun pada tabel diatas menjelaskan bahwa Bank BRI Syariah Tbk (BRI Syariah) kembali menerima penghargaan diacara Top Brand Award 2019 kategori Tabungan Syariah yang diselenggarakan oleh Majalah Marketing dan Frontier Consulting Group. Sekretaris BRI Syariah, Indriati Tri Handayani mengatakan penghargaan tersebut dimenangkan oleh BRI Syariah setelah berhasil berkompetisi dengan perusahaan perbankan lainnya. Penyerahan penghargaan ini dilakuan di
Hotel Mulia, Senayan, Jakarta, Jumat $(15 / 2)$.

\section{B. TINJAUAN PUSTAKA \\ 1. Pemasaran}

Pemasaran adalah suatu proses sosial yang didalamnya individu dan kelompok mendapat apa yang mereka butuhkan dan inginkan dengan menciptakan, menawarkan dan secara bebas mempertukarkan produk yang bernilai dengan pihak lain (Kotler 2016) 
Pemasaran berhubungan dengan mengidentifikasi dan memenuhi kebutuhan manusia dan masyarakat. Salah satu definisi terpendek dari pemasaran adalah memenuhi kebutuhan secara menguntungkan, Sementara, Asosiasi Pemasaran Amerika menawarkan definisi formal tentang pemasaran, Pemasaran adalah satu fungsi organisasi dan seperangkat proses untuk menciptakan, mengomunikasikan, dan menyerahkan nilai kepada pelanggan dan mengelola hubungan pelanggan dengan cara menguntungkan organisasi dan pemilik saham (Kotler \& keller, 2015)

Menurut Day \&Wensley (1983) dalam Tjiptono (2014). fungsi pemasaran memprakarsai, menegosiasikan dan mengelola relasi pertukaran dengan key interest grups dalam rangka mewujudkan keunggulan bersaing berkesinambungan dalam pasar - pasar spesifik. Dari uraian diatas pemasaran adalah pertemuan antara penjual dan pembeli yang sama-sama menguntungkan satu sama lain dengan menawarkan suatu produk bebas, yang bertujuan untuk memenuhi kebutuhan pribadi.

\section{Pemasaran Jasa}

Jasa Pemasaran dalam suatu perusahaan memegang peranan yang sangat penting, karena pemasaran merupakan salah satu kegiatan yang dilakukan untuk mempertahankan kelangsungan hidup perusahaan, melakukan perkembangan terhadap perusahaan dan untuk pencapaian tujuan perusahaan untuk memperoleh laba. Masyarakat awam pada umumnya seringkali menyamakan pemasaran dengan penjualan. Jasa merupakan tindakan atau kegiatan yang mencakup semua aktivitas yang output nya berupa kinerja (hasil) yang diterima oleh pelanggan atau konsumen.

Menurut Yazid (2016) pemasaran jasa merupakan penghubung antara organisasi dengan konsumennya. Peran penghubung ini akan berhasil bila semua upaya pemasaran diorientasikan kepada pasar. Keterlibatan semua pihak, dari manajemen puncak hingga karyawan non-manajerial, dalam merumuskan maupun mendukung pelakasanaan pemasaran yang berorientasi kepada konsumen tersebut merupakan hal yang tidak bisa ditawar-menawar lagi.

\section{Adapun pendapat Christoper Lovelock} \& Lauren $K$ Wright Pemasaran jasa merupakan bagian dari sistem jasa secara keseluruhan yaitu dimana perusahaan tersebut memiliki suatu kontak dengan pelanggannya, mulai dari pengiklanan hingga penagihan, hal itu mencakup kontak yang dilakukan pada saat penyerahan jasa. 
Dari uraian diatas dapat disimpulkan hubungan antara organisasi dengan konsumen secara kontak langsung mulai dari pengiklanan sampai penagihan dengan keterlibatan semua pihak.

\section{Customer Intimacy}

Customer Intimacy merupakan strategi popular yang digunakan oleh perbankan karena strategi ini merupakan strategi yang mampu menarik dan menjaga hubungan jangka panjang dengan para nasabahnya, Strategi Customer Intimacy juga yang dapat membedakan proses suatu pelayanan suatu perbankan walaupun menggunakan sistem yang sama yaitu syariat Islam (Feri Anggriawan : 2015).

Menurut gummesson (2000) Customer Intimacy adalah mendekatkan diri kepada nasabah. Customer Intimacy merupakan salah satu strategi popular yang digunakan perusahaan dalam membangun dan mempertahankan loyalitas nasabah. (Dian Oktavia, 2014).

Dari beberapa uraian diatas dapat disimpulkan customer intimacy adalah sebuah pendekatan nasabah dan mempertahankan loyalitas dengan cara menjaga hubungan komunikasi, perhatian, dan hubungan relasi yang baik.

\section{Customer Eksperience}

Schmitt (1999) Pengalaman Pelanggan (customer experience) merupakan tanggapan konsumen secara internal dan subyektif terhadap setiap hal yang berhubungan dengan perusahaan, baik secara langsung maupun tidak langsung. (Yanuar Fajarsunarimo

$\&$ Sumarsono,2014)

Menurut Meyer and Schwager (2007), customer experience adalah tanggapan pelanggan secara internal dan subjektif sebagai akibat dari interaksi secara langsung maupun tidak langsung dengan perusahaan. Reza (2016).

Sedangkan menurut Shaw dan Ivens (2002) Customer experience adalah perpaduan antara dua elemen yaitu fisikal dan emosional yang diterapkan perusahaan. (reza,2016).

Dari beberapa teori diatas dapat disimpulkan bahwa costumer experience (pengalaman pelanggan) adalah tanggapan pelanggan kepada perusahaan sebagai akibat interaksi secara langsung maupun tidak langsung terhadap setiap hal yang berhubungan dengan perusahaan.

\section{Customer Statication}

Menurut kotler (2016), Kepuasan adalah perasaan senang atau kecewa seseorang yang muncul setelah membandingkan antara persepsi atau kesan terhadap kinerja atau hasil suatu produk dan harapan-harapannya. Jadi, kepuasan merupakan fungsi dari persepsi atau kesan atas kinerja dan harapan. Jika kinerja berada dibawah harapan maka pelanggan 
tidak puas. Jika kinerja memenuhi harapan maka pelanggan akan puas. Jika kinerja melebihi harapan maka pelanggan akan amat puas atau senang.Kunci untuk menghasikan kesetian pelanggan adalah memberikan nilai pelanggan yang tinggi.

Hubungan antara kepuasan pelanggan dan pelanggan yang loyal adalah tidak proporsional, contohnya adalah kepuasan pelanggan yang diranking dengan skala 15, yaitu :

a. Kepuasan pelanggan pada tingkat sangat rendah (tingkat 1), kemungkinan besar pelanggan akan berpindah meninggalkan perusahaan dan menjelekjelekkannya.

b. Kepuasan pelanggan pada tingkat 2 sampai dengan tingkat 4 , pelanggan merasa agak puas,tetapi masih mungkin untuk berpindah ketika suatu penawaran lebih baik muncul.

c. Kepuasan pelanggan pada tingkat 5, pelanggan sangat mungkin membeli kembali dan bahkan menyebarluaskan kabar baik tentang perusahaan.Kesenangan atau kepuasan yang tinggi menciptakan suatu ikatan emosional dengan merek atau perusahaan tersebut dan tidak hanya terpaku pada pilihan yang masuk akal saja.

\section{Customer Bonding}

Marsudi (2004) customer bonding adalah semua aktivitas pemasaran untuk mengikat pelanggan bahwa produk yang ditawarkan atau dikonsumsi adalah satusatunya solusi yang dibutuhkan pelanggan sehingga pelanggan tidak pindah (migrate) ke produk lain.(Meyrina,2010). Sedangkan menurut cross dan smith (2007) yang menyatakan bahwa "Customer Bonding Strategy (Strategi mengikat pelanggan) adalah suatu strategi untuk menciptakan kepuasan dan loyalitas pelanggan pada produk dan perusahaan (Erina dan yulia, 2016).

Adapun teori lain didasarkan pada teori Simamora (2001) menyatakan customer bonding adalah strategi berpusat pada kesetiaan pelanggan, penampilan jujur perusahaan melalui media tertentu, dan pengalaman konsumen memakai produk atau jasa yang memenuhi atau melebihi harapan. (Damri, 2018).

\section{Loyalitas Nasabah}

Pada dasarnya loyalitas nasabah atau pelanggan akan mengalami penurunan dari waktu ke waktu, karena persaingan yang semakin kompetitif mengakibatkan konsumen dihadapkan banyak pilihan, baik value maupun fitur sejenis.

Lovelock and Wright (2005) loyalitas adalah keputusan pelanggan secara sukarela untuk terus berlangganan pada 
suatu merek produk atau jasa tertentu dalam jangka waktu yang lama. (iqbal ,dahlan dan kholid,2015).

Sedangkan menurut Griffin (2002) pelanggan yang loyal adalah mereka yang sangat puas dengan produk dan jasa tertentu sehingga mempunyai antusias untuk memperkenalkannya kepada siapapun yang mereka kenal. (Ferry, 2015)

\section{HIPOTESIS}

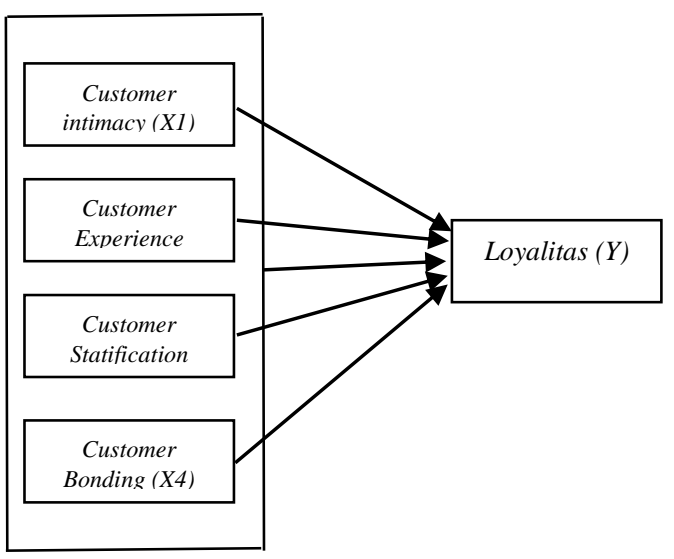

H1 : Diduga Customer Intimacy (X1) Berpengaruh signifikan terhadap Loyalitas H2 : Diduga Customer Experince (X2) Berpengaruh Signifikan terhadap Loyalitas H3 : Diduga Customer Statification (X3) Berpengaruh Signifikan terhadap Loyalitas H4 : Diduga Customer Bonding (X4) Berpengaruh Signifikan terhadap Loyalitas H4: Diduga Customer Intimacy, Customer Experince, Customer Statification, Customer Bonding, Berpengaruh Simultan terhadap Loyalitas

\section{METODE PENELITIAN}

jenis penelitian yang digunakan adalah penelitian penjelasan (explanatory research). penelitian ini menggunakan metode kuantitatif. Penelitian eksplanasi menurut (Syofian, 2013) adalah penelitian yang bermaksud menjelaskan kedudukan variabel-variabel yang diteliti serta hubungan atau pengaruh atau membandingkan satu variabel dengan variabel lain. Dengan demikian penelitian ini nantinya akan mengetahui sejauh mana pengaruh antar variabel yang sudah ditentukan. Alasan utama pemilihan jenis penelitian eksplanatori untuk menguji hipotesis yang diajukan agar dapat menjelaskan pengaruh variabel bebas (Customer intimacy, Customer Experience, Customer Statification, Customer Bonding) terhadap variabel terikat (Loyalitas nasabah) baik secara parsial maupun simultan yang ada dalam hipotesis tersebut. Sesuai dengan permasalahan, maka metode yang tepat untuk penelitian ini adalah studi kasus sebab studi metode kuantitatif adalah menjelaskan kedudukan variabel-variabel yang diteliti serta hubungan atau pengaruh atau membandingkan satu variabel dengan variabel lain atau yang dinamakan eksplanatory (hubungan sebab akibat) dengan menggunakan analisis Regresi Linier Berganda dengan persamaan :

$\mathrm{Y}=\mathrm{a}+\mathrm{b}_{1} \mathrm{X}_{1}+\mathrm{b}_{2} \mathrm{X}_{2}+\mathrm{b}_{3} \mathrm{X}_{3}+\mathrm{e}_{1}$

Penentuan Teknik Pengumpulan Data 
Adapun penulis mengambil populasi pada Bank BRI Syariah KCP Pandaan, disebabkan jumlah yang tidak pasti dan tidak diketahui berapa banyaknya jumlah nasabah yang ada di Bank BRI Syariah KCP Pandaan kabupaten Pasuruan.

Sampel adalah bagian dari karakteristik dan jumlah yang dimiliki oleh populasi, yang dapat mewakili karakteristik populasi tersebut. Bila populasi besar, dan penelitian tidak mungkin mempelajari semua yang ada pada populasi, misalnya karena keterbatasan tenaga dan waktu, untuk memenuhi akurasi hasil penyusunan indeks, maka penelitian ditetapkan dengan menggunakan rumus machin.

Teknik sampling merupakan teknik pengambilan sampel yang digunakan untuk menentukan sampel dalam penelitian (Sugiyono, 2013). Teknik pengambilan sampel dalam penelitian ini adalah dengan menggunakan pursosive sampling, yaitu teknik pengambilan sampel dimana setiap anggota populasi tidak memiliki kesempatan atau peluang yang sama sebagai sampel.

Berikut rumus Machin untuk menghitung sampel dalam penelitian ini :

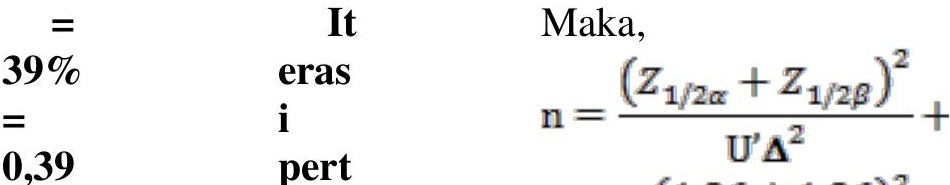

$$
\begin{aligned}
& \begin{array}{ll}
0,39 & \text { pert } \\
Z_{1 / 2 a} & \text { ama }
\end{array} \\
& \begin{array}{lll}
=\mathrm{U}^{\prime} \boldsymbol{\Delta}=1 / 2 \ln \left(\frac{1+\rho}{1-\rho}\right) & \mathrm{n}=\frac{(1,96+1,96)^{2}}{(0,4118000345)^{2}} \\
6 & & \begin{array}{l}
15,3664 \\
\mathrm{n}=1695792684
\end{array}+3
\end{array} \\
& ={ }^{Z_{1 / 2}}{ }^{\circ} \Delta=1 / 2 \ln \left(\frac{1+0,39}{1-0,39}\right)=93,61 \\
& 1 U^{\prime} \boldsymbol{\Delta}=1 / 2 \text { in }\left(\frac{1+0, \text {, 角9 }}{1-0,61}\right)^{93} \\
& \text {, = } \\
& 9 \quad 0,41180 \\
& 6 \quad 00345 \\
& \forall \\
& = \\
& 5 \\
& \%
\end{aligned}
$$

Iterasi kedua

$U^{2} \boldsymbol{\rho}=1 / 2 \ln \left(\frac{1+\boldsymbol{\rho}}{1-\boldsymbol{\rho}}\right)-U_{-}^{\prime} \rho \frac{\underline{\rho}_{1}}{\bar{n}-19} \ln \left(\frac{1+\boldsymbol{\rho}}{1-\boldsymbol{\rho}}\right)+\frac{1}{2(n}$ $U^{2} \rho=1 / 2 \ln \left(\frac{1+0,39}{1-0,39}\right) \rho=\frac{\rho}{2}\left(932-\ln 2\left(\frac{1+0,39}{1-0,39}\right)+\frac{1}{2}\right.$ $U^{2} \rho=1 / 2 \ln \left(\frac{1,39}{0,61}\right)+\frac{0,39}{184}=1 / 2 \ln \left(\frac{1,39}{0,61}\right)+\frac{0,39}{182}$

$$
\begin{array}{ll}
=0,4118000345 & = \\
+0,0021195652 & 0,4118000345 \\
=0,4139195997 & + \\
\text { Maka, } & 0,0021428571
\end{array}
$$$$
\mathrm{n}=\frac{\left(Z_{1 / 2 \alpha}+Z_{1 / 2 \beta}\right)^{2}}{U^{v} \Delta^{2}}+\underset{0,4139428916}{\text { Maka, }}
$$$$
\mathrm{n}=\frac{(1,96+1,96)^{2}}{(0,3902192162)^{2}}+3=\frac{\left(Z_{1 / 2 \alpha}+Z_{1 / 2 \beta}\right)^{2}}{U^{\prime} \Delta^{2}}+3
$$$$
\mathrm{n}=\frac{15,3664}{0,171329435}+3 \mathrm{n}=\frac{(1,96+1,96)^{2}}{(0,4139428916)^{2}}+3
$$$$
\begin{aligned}
& \mathrm{n}= \\
& \begin{array}{l}
92,689200224 \\
\mathrm{n}=92
\end{array} \quad \mathrm{n}=\frac{15,3664}{0,171348718}+3
\end{aligned}
$$$$
\mathrm{n}=
$$$$
\text { 92,679106908 }
$$$$
\mathrm{n}=92
$$
$\mathrm{n}=92$ 


\section{Ad-Deenar}

Karena pada literasi kedua dan ketiga nilai $\mathrm{n}$ sudah sama maka perhitungan literasi berhenti. Berdasarkan perhitungan diatas maka sampel dalam penelitian ini sebanyak 92 responden.

\section{Uji t}

uji $t$ digunakan untuk membandingkan mean atau nilai rata- rata sampel yang diamati dengan nialai ratarata yang diharapkan secara normal daridistribusi nilai rata-rata. Singkatnya, uji t membandingkan nialai rata- rata satu sama lain untuk menentukan adanya signifikansi statistik (Morissan, 2012). Bila $t_{\text {hitung }}$ lebih besar dari tabel signifikannya ( $p$ value) lebih kecil dari 5\% $(\alpha: 5 \%=0,05)$, maka hal ini menunjukan H0 ditolak. Hal ini berarti ada pengaruh signifikan antara variabel independen secara parsial. Rumus Uji t (Nachrowi, 2006).

\section{Uji F}

Uji F dimaksudkan untuk melihat kemampuan menyeluruh dari variabel bebas untuk dapat atau mampu menjelaskan tingkah laku atau keragaman vari abel $\mathrm{Y}$ dan juga dimaksudkan untuk mengetahui apakah semua variabel bebas memiliki koefisien regresi sama dengan nol (Suharyadi,2004).

\section{Uji Koefisian Determinasi R}

Koefisien determinasi $\left(\mathrm{R}^{2}\right)$ pada intinya mengukur seberapa jauh kemampuan model dalam menerangkan variasi variabel dependen. Nilai koefisien determinasi adalah antara 0-1. Nilai $\mathrm{R}^{2}$ yang kecil berarti kemampuan variabelvariabel independen dalam menjelaskan variasi variabel dependen amat terbatas. Nilai yang mendekati satu berarti variabelvariabel independen memberikan hampir semua informasi yang dibutuhkan untuk memprediksi variasi variabel dependen (Ghozali, 2009).

\section{PEMBAHASAN}

Tabel

Hasil Uji Validitas

\begin{tabular}{|c|c|c|c|c|c|}
\hline $\begin{array}{l}\mathrm{N} \\
\mathrm{o}\end{array}$ & $\begin{array}{c}\text { Variabe } \\
1\end{array}$ & $\begin{array}{l}\text { Ite } \\
\mathrm{m}\end{array}$ & $\begin{array}{c}\text { Koefis } \\
\text { ien } \\
\text { korel } \\
\text { asi } \\
(\mathrm{r}) \\
\end{array}$ & $\begin{array}{l}\mathrm{Si} \\
\mathrm{g} .\end{array}$ & $\begin{array}{l}\text { Keteran } \\
\text { gan }\end{array}$ \\
\hline \multirow[t]{10}{*}{1} & \multirow{10}{*}{$\begin{array}{c}\text { Custom } \\
\text { er } \\
\text { Intimac } \\
y \text { (X1) }\end{array}$} & $\begin{array}{c}\mathrm{X} 1 . \\
1\end{array}$ & 0,915 & $\begin{array}{c}0,0 \\
00\end{array}$ & Valid \\
\hline & & $\begin{array}{c}\mathrm{X} 1 . \\
2\end{array}$ & 0,611 & $\begin{array}{r}0,0 \\
00\end{array}$ & Valid \\
\hline & & $\begin{array}{c}\mathrm{X} 1 . \\
3\end{array}$ & 0,729 & $\begin{array}{r}0,0 \\
00\end{array}$ & Valid \\
\hline & & $\begin{array}{c}\mathrm{X} 1 . \\
4\end{array}$ & 0,915 & $\begin{array}{c}0,0 \\
00\end{array}$ & Valid \\
\hline & & $\begin{array}{c}\mathrm{X} 1 . \\
5\end{array}$ & 0,930 & $\begin{array}{r}0,0 \\
00\end{array}$ & Valid \\
\hline & & $\begin{array}{c}\mathrm{X} 1 . \\
6\end{array}$ & 0,806 & $\begin{array}{r}0,0 \\
00\end{array}$ & Valid \\
\hline & & $\begin{array}{c}X 1 . \\
7\end{array}$ & 0,798 & $\begin{array}{r}0,0 \\
00\end{array}$ & Valid \\
\hline & & $\begin{array}{c}\mathrm{X} 1 . \\
8\end{array}$ & 0,725 & $\begin{array}{c}0,0 \\
00\end{array}$ & Valid \\
\hline & & $\begin{array}{c}\mathrm{X} 1 . \\
9\end{array}$ & 0,592 & $\begin{array}{r}0,0 \\
00 \\
\end{array}$ & Valid \\
\hline & & $\begin{array}{r}\mathrm{X} 1 . \\
10\end{array}$ & 0,924 & $\begin{array}{r}0,0 \\
00\end{array}$ & Valid \\
\hline 2 & $\begin{array}{c}\text { Custom } \\
\text { er }\end{array}$ & $\begin{array}{c}\mathrm{X} 2 . \\
1\end{array}$ & 0,849 & $\begin{array}{r}0,0 \\
00\end{array}$ & Valid \\
\hline
\end{tabular}




\begin{tabular}{|c|c|c|c|c|c|}
\hline $\begin{array}{l}\mathrm{N} \\
\mathrm{O}\end{array}$ & $\begin{array}{c}\text { Variabe } \\
1\end{array}$ & $\begin{array}{c}\text { Ite } \\
\mathrm{m}\end{array}$ & $\begin{array}{c}\text { Koefis } \\
\text { ien } \\
\text { korel } \\
\text { asi } \\
\text { (r) }\end{array}$ & $\begin{array}{l}\mathrm{Si} \\
\mathrm{g} .\end{array}$ & $\begin{array}{c}\text { Keteran } \\
\text { gan }\end{array}$ \\
\hline & \multirow{8}{*}{$\begin{array}{c}\text { Experie } \\
\text { nce } \\
\text { (X2) }\end{array}$} & $\begin{array}{c}\mathrm{X} 2 . \\
2\end{array}$ & 0,569 & $\begin{array}{r}0,0 \\
00\end{array}$ & Valid \\
\hline & & $\begin{array}{c}\mathrm{X} 2 . \\
3\end{array}$ & 0,743 & $\begin{array}{r}0,0 \\
00 \\
\end{array}$ & Valid \\
\hline & & $\begin{array}{c}\mathrm{X} 2 . \\
4\end{array}$ & 0,830 & $\begin{array}{r}0,0 \\
00\end{array}$ & Valid \\
\hline & & $\begin{array}{c}X 2 . \\
5\end{array}$ & 0,790 & $\begin{array}{r}0,0 \\
00\end{array}$ & Valid \\
\hline & & $\begin{array}{c}\mathrm{X} 2 . \\
6\end{array}$ & 0,840 & $\begin{array}{c}0,00 \\
0\end{array}$ & Valid \\
\hline & & $\begin{array}{c}\mathrm{X} 2 . \\
7\end{array}$ & 0,819 & $\begin{array}{c}0,00 \\
0\end{array}$ & Valid \\
\hline & & $\begin{array}{c}\mathrm{X} 2 . \\
8\end{array}$ & 0,797 & $\begin{array}{c}0,00 \\
0\end{array}$ & Valid \\
\hline & & $\begin{array}{c}\mathrm{X} 2 . \\
9\end{array}$ & 0,838 & $\begin{array}{c}0,00 \\
0\end{array}$ & Valid \\
\hline \multirow[t]{5}{*}{3} & \multirow{5}{*}{$\begin{array}{c}\text { Custom } \\
\text { er } \\
\text { Satisfac } \\
\text { tion } \\
\text { (X3) }\end{array}$} & $\begin{array}{c}\text { X3. } \\
1\end{array}$ & 0,725 & $\begin{array}{c}0,00 \\
0\end{array}$ & Valid \\
\hline & & $\begin{array}{c}\text { X3. } \\
2\end{array}$ & 0,592 & $\begin{array}{c}0,00 \\
0\end{array}$ & Valid \\
\hline & & $\begin{array}{c}\text { X3. } \\
3\end{array}$ & 0,924 & $\begin{array}{c}0,00 \\
0\end{array}$ & Valid \\
\hline & & $\begin{array}{c}\text { X3. } \\
4\end{array}$ & 0,849 & $\begin{array}{c}0,00 \\
0\end{array}$ & Valid \\
\hline & & $\begin{array}{c}\text { X3. } \\
5\end{array}$ & 0,569 & $\begin{array}{c}0,00 \\
0\end{array}$ & Valid \\
\hline \multirow[t]{5}{*}{4} & \multirow{5}{*}{$\begin{array}{c}\text { Custom } \\
\text { er } \\
\text { Bondin } \\
g(\mathrm{X} 4)\end{array}$} & $\begin{array}{c}\text { X4. } \\
1\end{array}$ & 0,799 & $\begin{array}{c}0,00 \\
0\end{array}$ & Valid \\
\hline & & $\begin{array}{c}\text { X4. } \\
2\end{array}$ & 0,853 & $\begin{array}{c}0,00 \\
0\end{array}$ & Valid \\
\hline & & $\begin{array}{c}\text { X4. } \\
3\end{array}$ & 0,748 & $\begin{array}{c}0,00 \\
0\end{array}$ & Valid \\
\hline & & $\begin{array}{c}\text { X4. } \\
4\end{array}$ & 0,928 & $\begin{array}{c}0,00 \\
0\end{array}$ & Valid \\
\hline & & $\begin{array}{c}\text { X4. } \\
5\end{array}$ & 0,915 & $\begin{array}{c}0,00 \\
0\end{array}$ & Valid \\
\hline \multirow[t]{4}{*}{5} & \multirow{4}{*}{$\begin{array}{c}\text { Loyalit } \\
\text { as } \\
\text { Nasaba } \\
\text { h } \\
\text { (Y) }\end{array}$} & $\mathrm{Y} 1$ & 0,620 & $\begin{array}{c}0,00 \\
0\end{array}$ & Valid \\
\hline & & $\mathrm{Y} 2$ & 0,644 & $\begin{array}{c}0,00 \\
0\end{array}$ & Valid \\
\hline & & Y3 & 0,696 & $\begin{array}{c}0,00 \\
0\end{array}$ & Valid \\
\hline & & Y4 & 0,681 & $\begin{array}{c}0,00 \\
0\end{array}$ & Valid \\
\hline
\end{tabular}

Sumber: Data Primer, diolah 2019

Tabel

Uji Reliabilitas

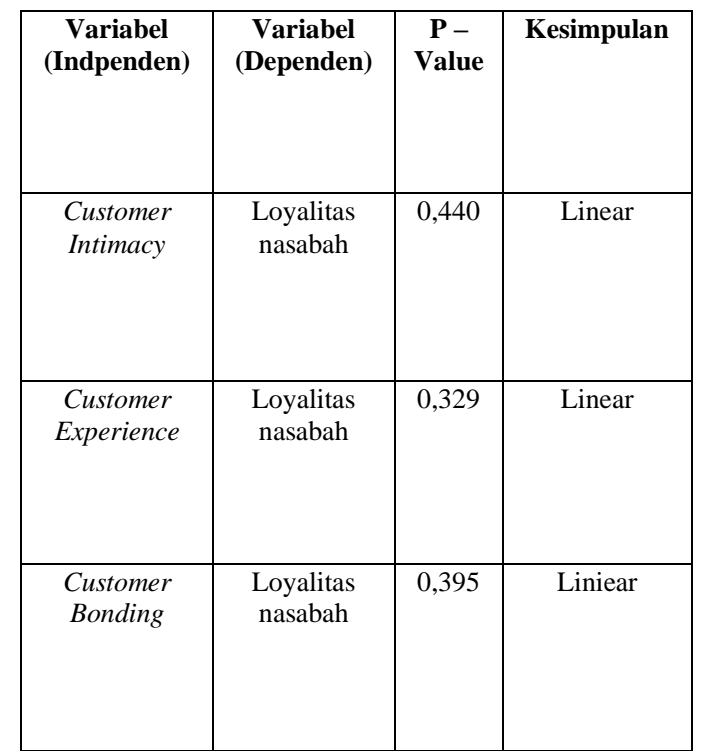

Sumber : Data primer, diolah 2019

Uji Asumsi Klasik

Uji Linieritas

Tabel

\section{Hasil Uji Linieritas}

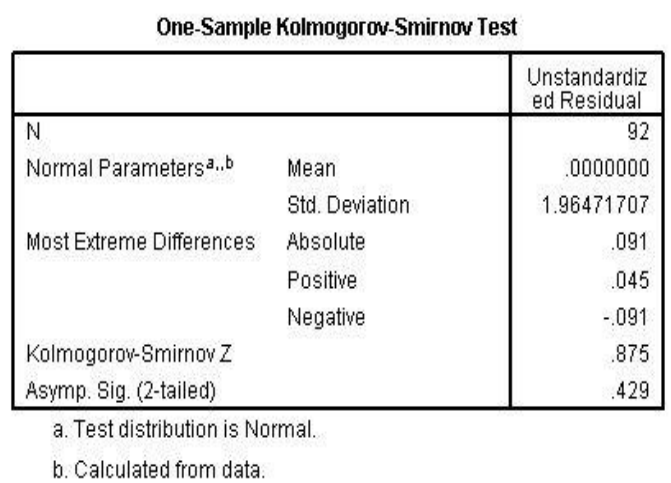

Sumber : data primer, diolah 2019

\section{Uji Normalitas}

Berdasarkan tabel diatas hasil uji normalitas dapat diketahui nilai sig. sebesar 0,429 lebih besar dari taraf signifikansi yang digunakan yaitu $(0,05)$ 
maka dapat disimpulkan bahwa data berdistribusi normal.

\section{Tabel}

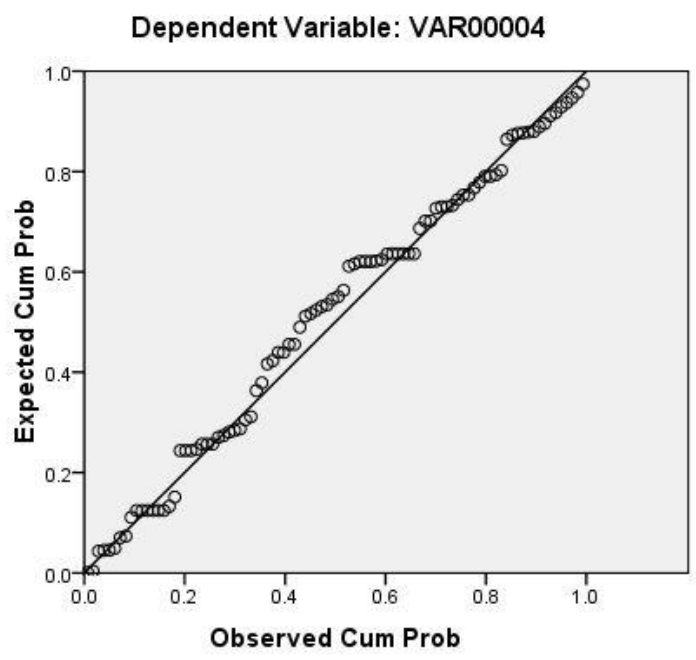

Uji Multikolinearitas

Pada tabel diatas bahwa dasar pengambilan keputusan dalam uji multikolinearitas $\mathrm{i}$

\section{Hasil Uji Normalitas Gambar Hasil uji Normalitas}

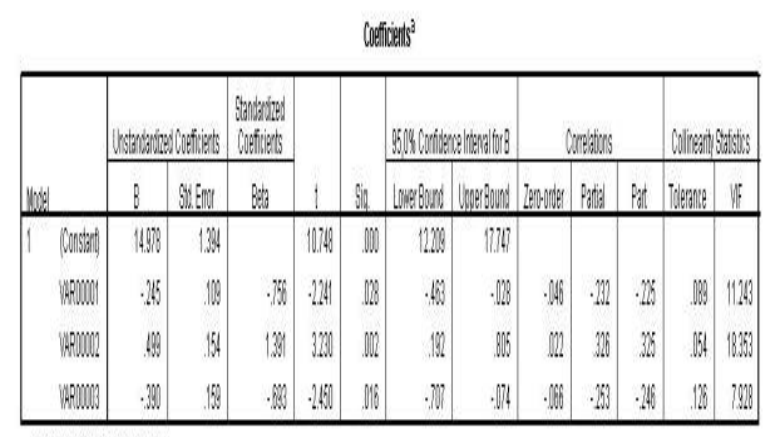

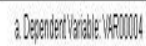

\section{Sumber : Data primer, diolah 2019}

Dari gambar diatas dapat disimpulkan bahwa jika data yang berupa titik-titik menyebar disekitar garis diagonal dan mengikuti arah garis diagonal atau grafik histogramnya menunjukkan pola distribusi normal, maka model regresi pada penelititian ini memenuhi asumsi normalitas.

Pada tabel diatas bahwa dasar pengambilan keputusan dalam uji multikolinearitas ini dapat dilakukan dengan cara melihat nilai VIF dan Tolerance. Hasil perhitungan nilai Tolerance tidak ada variabel independen yang memiliki nilai Tolerance kurang dari 0.10 dengan masing-masing variabel independen. Untuk variabel Customer Intimacy $\left(\mathrm{X}_{1}\right)$ 0,089, variabel Customer Experience $\left(\mathrm{X}_{2}\right)$ 0,054, variabel Customer Bonding $\left(\mathrm{X}_{3}\right)$ 0,126. Sementara, nilai VIF juga menunjukan hal serupa yaitu tidak adanya nilai VIF dari variabel independen yang memiliki nilai lebih dari 10, dengan masing-masing bernilai untuk variabel Customer Intimacy $\left(\mathrm{X}_{1}\right)$ 11.243, variabel Customer Experience $\left(\mathrm{X}_{2}\right) 18.353$, variabel Customer Bonding7928. Merujuk hasil perhitungan nilai Tolerance dan VIF dapat disimpulkan bahwa tidak ada multikolinearitas antar variabel independen dalam model regresi 


\section{Uji Heterokedastisitas}

\section{Gambar}

\section{Hasil uji heteroskedastisitas}

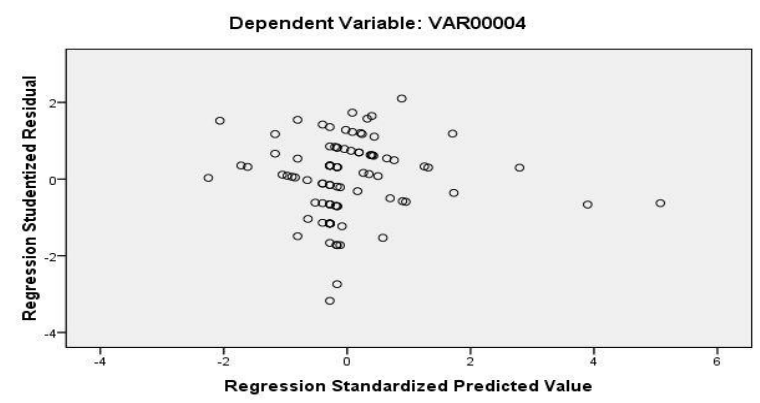

\section{Sumber : Data primer, diolah 2019}

Berdasarkan gambar diatas terllihat bahwa tidak ada pola yang jelas serta titiktitik tersebut menyebar diatas dan dibawah angka 0 pada sumbu $Y$. Hal ini menunjukan bahwa data dalam penelitian ini tidak terjadi heteroskedastisitas.

\section{Hasil Analisis Linier Berganda}

Pengujian regresi linear berganda berguna untuk mengetahui tingkat pengaruh variabel independen (Cectomer Intimacy, Customer Experience,Customer Satifaction Customer Bonding) terhadap variabel dependen (Loyalitas Nasabah). Berdasarkan pengujian diperoleh hasil yang dapat disajikan dalam tabel berikut:

Tabel Hasil Analisis Regresi Linier Berganda

\begin{tabular}{|c|c|c|c|c|c|}
\hline Variabel & $\begin{array}{c}\text { Koef. } \\
\text { Regres } \\
\text { i }\end{array}$ & $\mathbf{t}_{\text {hitung }}$ & $\mathbf{t}_{\text {tabel }}$ & Sig. & $\begin{array}{c}\text { Keteran } \\
\text { gan }\end{array}$ \\
\hline Konstanta & 14.978 & & & .000 & \\
\hline $\begin{array}{l}\text { Customer } \\
\text { Intimacy }\end{array}$ & -.245 & $\begin{array}{c}- \\
2.24 \\
1\end{array}$ & $\begin{array}{c}1,98 \\
6\end{array}$ & .028 & $\begin{array}{c}\text { Signifika } \\
\mathrm{n}\end{array}$ \\
\hline $\begin{array}{c}\text { Customer } \\
\text { Experienc } \\
e \\
\end{array}$ & 499 & $\begin{array}{c}3.23 \\
0\end{array}$ & $\begin{array}{c}1,98 \\
6\end{array}$ & .002 & $\begin{array}{c}\text { Signifika } \\
\mathrm{n}\end{array}$ \\
\hline $\begin{array}{l}\text { Customer } \\
\text { Satisfactio }\end{array}$ & 399 & $\begin{array}{c}3.24 \\
4\end{array}$ & $\begin{array}{c}1,98 \\
6\end{array}$ & .004 & $\begin{array}{c}\text { Signifika } \\
\mathrm{n}\end{array}$ \\
\hline
\end{tabular}

\begin{tabular}{|c|c|c|c|c|c|}
\hline$n$ & & & & & \\
\hline $\begin{array}{c}\text { Customer } \\
\text { Bonding }\end{array}$ & -.390 & - & 1,98 & .016 & Signifika \\
& & $\begin{array}{c}2.45 \\
0\end{array}$ & 6 & & $\mathrm{n}$ \\
\hline
\end{tabular}

Sumber : Data primer, diolah 2019.

Berdasarkan hasil tersebut dapat diperoleh persamaan regresi linier berganda sebagai berikut :

$\begin{array}{cc}\mathrm{Y}=14.978+-0,245 \mathrm{X}_{1} \text { (Customer } \\ \text { intimacy) }+499 \mathrm{X}_{2} \text { (Customer Experience) }+ \\ 399 \mathrm{X}_{3} \text { (Customer Satifaction) } & +-0,390 \mathrm{X}_{3} \\ \text { (Customer Bonding) }+\mathrm{e} & \\ \text { Keterangan : } & \mathrm{X} 3= \\ \mathrm{Y}= & \text { Custome } \\ \text { Loyalita } & r \\ \mathrm{~s} & \text { Satisfacti } \\ \text { Nasabah } & \text { on } \\ \mathrm{X} 1 \quad= & \mathrm{X} 4 \\ \text { Custome } & \text { Custome } \\ r & r \\ \text { Intimacy } & \text { Bonding } \\ \mathrm{X} 2 & \\ \text { Custome } & \\ r & \\ \text { Experien } & \\ \text { ce } & \end{array}$

Dari persamaan diatas diketahui :

a. Koefisien regresi variabel customer intimacy diketahui sebesar -0,245 adalah negative, artinya semakin lemah pengaruh variabel Customer Intimacy, maka semakin rendah Loyalitas nasabah. Sebaliknya semakin kuat pengaruh variabel Customer Intimacy maka semakin meningkatkan Loyalitas nasabah.

b. Koefisien regresi variabel Customer experience diketahui sebesar 499 adalah positive, artinya semakin kuat pengaruh variabel 
customer experience, maka semakin rendah Loyalitas Nasabah.

Sebaliknya semakin lemah pengaruh variabel customer experience maka semakin menurunkan loyalitas nasabah

c. Koefisien regresi variabel Customer Satifaction diketahui sebesar 399 adalah positive, artinya semakin kuat pengaruh variabel customer experience, maka semakin rendah Loyalitas Nasabah. Sebaliknya semakin lemah pengaruh variabel customer Satifaction maka semakin menurunkan loyalitas nasabah

d. Koefisien regresi variabel Customer Bonding diketahui sebesar -0,390 adalah negative, artinya semakin lemah pengaruh variabel Customer Bonding, maka semakin rendah Loyalitas nasabah. Sebaliknya semakin kuat pengaruh variabel Customer Bonding maka semakin meningkatkan Loyalitas nasabah.

\section{Pengaruh Customer Intimacy terhadap Loyalitas Nasabah}

Hasil pengujian hipotesis Customer Intimacy $\left(\mathrm{CI}_{1}\right)$ telah memberikan bukti bahwa tidak terdapat pengaruh positif signifikan antara Customer Intimacy terhadap Loyalitas nasabah. Berdasarkan hasil perhitungan yang telah diperoleh melalui uji t memiliki nilai sebesar -2.241 $<\mathrm{t}$ tabel $(1,660)$ dengan koefisien regresi sebesar $-2,45$ dan taraf signifikan sebesar 0,28 kurang dari 0,05 dengan demikian hipotesis ditolak karena arah koefisiennya yang negatif. Pengujian ini secara statistic membuktikan variabel Customer Intimacy tidak berpengaruh positif signifikan terhadap loyalitas nasabah.

Hasil penelitian ini mendukung yang dilakukan oleh I kadek oka Sucandra dengan judul "pengaruh customer intimacy terhadap loyalitas pelanggan" dari hasil tersebut mengatakan bahwa variabel customer intimacy tidak berpengaruh positif signifikan terhadap loyalitas nasabah.

\section{Pengaruh Customer Experience terhadap Loyalitas Nasabah}

Hipotesis yang menyatakan bahwa variabel Customer Experience secara parsial berpengaruh positif signifikan dapat diterima hal ini dapat dibuktikan dengan hasil uji t dimana nilai sig $(0,002)$ lebih kecil dari standart signifikasi 0,05 dan $\mathrm{t}-$ hitung sebesar $3.230>\mathrm{t}$ tabel (1.666) yang menunjukkan hasil yang positif signifikan.

Hasil penelitian ini mendukung dari hasil penelitian terdahulu Muhammad iqbal azhari, dahlan fanani, M.kholid mawardi, "pengaruh Customer experience terhadap kepuasan pelanggan dan 
loyalitas pelanggan" dalam penelitian tersebut variabel Customer Experience memiliki pengaruh positif signifikan terhadap loyalitas nasabah.

\section{Pengaruh Customer Satifaction terhadap Loyalitas Nasabah}

Hipotesis yang menyatakan bahwa variabel Customer Satifaction secara parsial berpengaruh positif signifikan dapat diterima hal ini dapat dibuktikan dengan hasil uji t dimana nilai sig $(0,002)$ lebih kecil dari standart signifikasi 0,05 dan $\mathrm{t}-$ hitung sebesar $3.244>\mathrm{t}$ tabel (1.666) yang menunjukkan hasil yang positif signifikan.

Hasil penelitian ini mendukung dari hasil penelitian terdahulu Muhammad iqbal azhari, dahlan fanani, M.kholid mawardi, "pengaruh Customer experience terhadap kepuasan pelanggan dan loyalitas pelanggan" dalam penelitian tersebut variabel Customer Experience memiliki pengaruh positif signifikan terhadap loyalitas nasabah.

\section{Pengaruh Customer Bonding terhadap Loyalitas Nasabah}

Hipotesis yang menyatakan bahwa Customer Bonding secara parsial berpengaruh negatif signifikan terhadap Loyalitas Nasabah. Hal ini dapat dibuktikan dengan hasil uji $\mathrm{t}$ dimana nilai sig $(0,16)$ lebih kecil dari standart signifikasi 0,05 yang menunjukkan hasil signifikan dan $\mathrm{t}-$ hitung sebesar $-2.450<\mathrm{t}$ tabel yang menunjukkan hasil negative.
Hasil penelitian ini tidak mendukung dari hasil penelitian terdahulu Damri.SM (2018) "pengaruh strategi Customer bonding terhadap loyalitas nasabah PT. Bank Negara Indonesia (persero) tbk (studi pada nasabah taplus bisnis kantor cabang pekanbaru) hasil dari penelitian ini menunjukkan bahwa lima item (awareness, identity, relationship, community, dan advocacy,) Customer bonding tidak memiliki pengaruh positif dan signifikan.

Pengaruh Customer Intimacy, Customer Experience, Customer Satisfaction, Customer Bonding, terhadap Loyalitas Nasabah

Hipotesis yang menyatakan bahwa pengaruh Customer Intimacy, Customer Experience,

Customer

Satisfaction,Customer Bonding secara simultan berpengaruh positif dan signifikan terhadap Loyalitas nasabah di bank BRI Syariah KCP Pandaan. Dapat diterima hal ini juga dapat dibuktikan dengan hasil uji $\mathrm{F}$ dengan nilai signifikan 0,016 lebih kecil dari standart 0,05 yang menunjukkan hasil yang signifikan artinya pengaruh Customer Intimacy, Customer Experience, Customer Bonding memiliki pengaruh signifikan terhadap Loyalitas Nasabah.

Didapatkan nilai F hitung $3.652>$ dari F tabel 3.10 mengindikasikan pengaruh Customer Intimacy, Customer Experience, , Customer Satisfaction, Customer bonding 
terhadap loyalitas nasabah adalah positif maka dapat disimpulkan bahwa semakin baik, Customer Intimacy, Customer Experience, Customer bonding. Maka semakin tinggi pula Loyalitas di Bank BRI Syariah KCP Pandaan.

\section{E. KESIMPULAN}

Berdasarkan uraian-uraian yang telah diungkapkan pada pembahasan, maka dapat diambil beberapa kesimpulan sebagai jawaban atas pokok permasalahan yang diajukan dalam penelitian ini, yaitu:

1. Customer Intimacy secara parsial berpengaruh negatif dan signifikan terhadap loyalitas nasabah

2. Customer Experience secara parsial berpengaruh positif dan signifikan terhadap loyalitas nasabah

3. Customer Satifaction secara parsial berpengaruh positif dan signifikan terhadap loyalitas nasabah

4. Customer Bonding secara parsial berpengaruh negatif dan signifikan terhadap loyalitas nasabah

5. Customer Intimacy, Customer Experience, Customer Satifaction dan Customer Bonding, secara simultan berpengaruh positif dan signifikan terhadap loyalitas nasabah.

\section{DAFTAR PUSTAKA}

Anggriawan, F. (2015). Pengaruh Customer Intimacy Terhadap Loyalitas Nasabah Bank Rakyat Indonesia Syahriah Cabang Jember.

Azhari, M. I., Fanani, D., \& Mawardi, M. K. (2015). Pengaruh Customer Experience Terhadap Kepuasan Pelanggan dan Loyalitas Pelanggan (Survei Pada Pelanggan Kfc Kawi Malang). fakultas ilmu administrasi Universitas Brawijaya malang.

Bunging B. (2013). Metodologi Penelitian Sosial dan Ekonomi: Format-Format Kuantitatif dan Kualitatif Untuk Studi Sosiologi, Kebijakan publik, Komunikasi, Managemen, dan Pemasaran. Jakarta : Predana Media Group.

DAMRI.SM. (2018). Pengaruh Strategi Customer Bonding Terhadap Loyalitas (Studi Pada Nasabah Taplus Bisnis Kantor Cabang Pekanbaru). MENARA Ilmu .

Erina, \& efi, Y. (2016). Pengaruh Strategi Customer Bonding Terhadap Customer Satisfaction Dan Customer Loyalty Pada Pt. Bank Rakyat Indonesia (Persero) Tbk.(Survey Pada Nasabah Tabungan Britama Kantor Cabang Teluk Kuantan). Jurnal Tepak Manajemen Bisnis.

Fajarsunarimo, y., \& sumarsono. (2014). pengaruh pengalaman pelanggan, komunikasi pemasaran dan kepuasan pelanggan terhadap loyalitas merek pada restoran merah putih purwokerto. performance, 19.

Fandy Tjiptono, Ph.D (2014). Pemasaran Jasa. Yogyakarta, C.V ANDI OFFSET.

Kotler, Philip. (1997). Manajemen Pemasaran. Jakarta: PT. Prenhallindo 
Kotler, Philip \& Kevin L.Keller. (2007). Manajemen pemasaran. edisi 12 jilid 1, Edittion.

Ghozali, Imam. (2009). Aplikasi Analisis Multivariate Dengan Program SPSS, Edisi Keempat, Penerbit Universitas Diponegoro.

Kristanto, K., \& Adiwijaya, M. 2018. Pengaruh Kualitas, Harga, Dan Pengalaman Pelanggan Terhadap Loyalitas Pelanggan Pada Rumah Makan Leko . Agora .

Kotler, Philip \& Kevin L. Keller, 2009. Manajemen Pemasaran edisi 13 jilid 1. Jakarta, ERLANGGA.

Kuncoro, Mudrajad. (2003). Metode Riset untuk Bisnis dan Ekonomi. Jakarta: Erlangga.

Morrisan. (2015). Metode Penelitian Survei. Jakarta: Kencana

Nurmizana, M. (2010). Pengaruh Customer Bonding Terhadap Loyalitas Pelanggan Loyalitas Pelanggan Matahari Club Card (Mcc) Di Matahari Department Store Java Mall Semarang.

Nachrowi. (2006). Pendekatan Populer dan Praktis Ekonometrika Untuk Analisis Ekonomi dan Keluarga. Fakultas Ekonomi Universitas Indonesia.

Pearson International Edition. Prentice Hall: new jersey. PT Macanan Jaya Cemerlang

ROZI, A. F. (2012). Pengaruh Customer Intimacy Dan Kepercayaan Serta Komitmen Terhadap Loyalitas Nasabah Bank Jatim Cabang Jember.

SUCANDRA, I. K. (2016). Pengaruh Customer Intimacy Terhadap Loyalitas Pelanggan (Survei Pada Pelanggan Toko Lampung Tengah).

Setiadi. J. Nugroho. (2015). Perilaku Konsumen edisi revisi. Prenada Media Grup.Jakarta
Sugiyono. (2012). Metode Penelitan Kuantitatif, Kualitatif dan R\&B (2012). Bandung, Alfabeta

Suharyadi. (2004). Statistik Untuk Ekonomi \& Keuangan Modern. Jakarta: Salemba Empat.

Siregar, Syofian. (2013). Metode Penelitian Kuantitatif. Jakarta: Kencana.

Sugiyono, (2017). Metode Penelitan Kuantitatif, Kualitatif dan R\&B (2012). Bandung, ALFABETA, cv

Wardhana, R. e. (2016). ggan Sebagai Variabel Intervening (Studi Pada Konsumen Mie Rampok Tahanan Surabaya). jurnal ilmu manajemen volume 4 nomor 3 .

https://www.kajianpustaka.com/2018/11/tu juan-karakteristik-jenis-dan-strategipemasaran-jasa.html

https://www.akuntansilengkap.com/pemas aran/pengertian-karakteristik-sertastrategi-pemasaran-jasa/

https://cerdaswirausaha.wordpress.com/20 11/06/12/a-karakteristik-pemasaranjasa/

https://www.sharianews.com/posts/tabungansyariah-terbaik-bri-syariah-raih-topbrand-award-2019

www.cnbcindonesia.com/market/201904041 30637-17-64612/laba-bank-brisyariah-capairp-1066-m-cuma-naik-54 
